\title{
Ana Fani Alessandri Carlos
}

Professora titular de Geografia Humana, Universidade de São Paulo

anafanic@usp.br

\section{Metamorfoses urbanas}

A cidade é a civilização em ação realizando-se contraditoriamente. A história da cidade no Brasil, nas últimas duas décadas, é aquela do aprofundamento da crise ligada a nossa condição de dependência em relação aos paises centrais.

Quando nos debruçamos sobre a cidade nos defrontamos com a inexorabilidade de suas transformações, mas, sob o signo da modernidade, o tempo das transformações se acelera. Nas últimas décadas, as mudanças ocorrem num ritmo muito mais rápido e tem sua explicação no modo como a globalização se realiza redirecionando a vida sustentada no paradigma da efemeridade do tempo que, acelerado pela técnica, produziu sua própria abstração. Mas o processo não se reduz às mudanças temporais, revela-se de forma significativa no espaço. Ao se expandir, o capitalismo produz, incessantemente, um novo espaço-tempo.

No Brasil, através da reprodução do espaço urbano, podemos perceber as mudanças que ocorrem no mundo moderno, tanto no que se refere às transformações das cidades, quanto da vida urbana, pois a realidade urbana revela-se enquanto prática sócio-espacial. Significa dizer, que do ponto de vista da Geografia, o processo de urbanização não se explicita pelo simples crescimento da cidade - através do movimento migratório, ou do comportamento demográfico -, mas em seus conteúdos: o modo de vida urbano com seus valores culturais e suas novas relações espaçotemporais. Nesta perspectiva, a vida urbana revela que as mudanças, nas 
duas últimas décadas, ocorrem numa velocidade maior do que a duração da vida do cidadão, trazendo, como conseqüência, a implosão dos referenciais que sustentam a vida, criando-lhe outros significados. Principalmente vivenciado nas grandes cidades brasileiras, esse processo rápido de mudança faz com que os cidadãos vivam um processo de estranhamento em relação à cidade que aparece como caos e desordem.

A extensão do capitalismo, com o desenvolvimento do valor de troca, como necessidade do processo ininterrupto de valorização, produziu o mundo da mercadoria e esta, como signo mediador das relações sociais, impondo às relações sociais sua lógica e linguagem. A própria produção do espaço como mercadoria através da generalização da propriedade privada subsumiu as formas de uso da cidade, capturando-lhe todos os momentos possíveis de apropriação - a vida se realiza cada vez mais no âmbito dos espaços privados. O processo de reprodução hoje saiu dos limites estreitos da fábrica para dominar, além do tempo e espaço do trabalho, o tempo/espaço de todos os momentos da vida cotidiana, capturando o tempo cíclico, agora sob a dominação do tempo linear, referenciado pela reestruturação produtiva, pelo aumento do desemprego promovido pela extinção dos empregos industriais, que marca as transformações em nossa sociedade. Hoje, o atual estágio de globalização, ao tornar o espaço produtivo, permitiu o esvaziamento dos usos do espaço da vida, na medida em que a produção da cidade se acha submetida ao valor de troca, condicionando seu uso ao mercado. Deste modo, no plano da prática sócio-espacial, a realização da propriedade privada, como forma condicionante da apropriação, redefine os usos dos espaços-tempos da vida cotidiana, orientando a prática sócio-espacial urbana às exigências da realização da reprodução capitalista.

Assim, o momento atual sinaliza uma profunda crise social pressentida pela deterioração das relações sociais, pela tendência ao escasseamento das relações de vizinhança, pela diminuição dos espaços de sociabilidade (aquele da rua, aquele do pequeno comércio de bairro, das praças), pela implosão do bairro, pela deterioração do espaço público, pelo esvaziamento da centralidade simbólica do centro histórico, pelo aumento das taxas de violência, promovido pela ascensão vertiginosa da pobreza e pelo crescimento da atividade do narcotráfico como setor importante da economia, 
trazendo, como conseqüência, o isolamento das pessoas em meio à idéia de sua proximidade, via espaço virtual. Com isto, o atual processo de urbanização tem por essência a negação do urbano e da vida urbana.

O mundo urbano revela, também, o aprofundamento da desigualdade social impresso nas formas da segregação sócio-espacial. A concentração da propriedade e da riqueza em poucas mãos marca a crescente desigualdade passível de ser lida na expansão dos espaços funcionalizados voltados à especialização e à separação espacial das atividades econômicas -, no aumento da construção dos condomínios fechados, pois a população de alto poder aquisitivo se tranca em condomínios onde os grandes muros criam a impressão de que podem se desligar dos outros, apartando-se. Nesta situação, o umbral da casa passa a marcar o limite entre o público e o privado. Esvaziados de seus conteúdos civilizatórios, o espaço público é representado, cada vez mais, como o espaço do medo, da violência, portanto, um lugar a ser evitado. Em conseqüência, a construção, quase sem limites, dos shopping centers, como espaços semi-públicos em sua sociabilidade restrita ou quase impossível. Na outra vertente, a explosão das periferias urbanas - em extensão e em população (crescendo com taxas superiores ás áreas centrais, apesar de ter seu ritmo diminuído na última década) - com a ocupação de morros, alagados, áreas de proteção de mananciais e várzeas, marcando um movimento de precarização eminente da habitação e da vida. Esse processo espacial que sinaliza o aprofundamento da segregação urbana se acelerou com a recessão dos anos 1980/90, momento em que o PIB brasileiro teve um crescimento per capita negativo.

No centro deste processo está a extensão, no espaço, da propriedade privada como pressuposto, condição e produto da reprodução social e elemento definidor dos conteúdos da prática sócio-espacial, posto que a extensão do capital se concretiza, realizando a lei do valor através da generalização do espaço-mercadoria, limitando seu acesso àqueles que podem comprá-lo. Nesta condição, criam-se espaços fragmentados, comprados e vendidos no mercado imobiliário, que vão sedimentando a desigualdade social, através da imposição da propriedade como condição de acesso neste processo a paisagem urbana revela a profunda diferenciação dos bairros na justaposição entre morfologia espacial/morfologia social. As- 
sim, a segregação torna-se mais clara - mas não exclusiva - no plano da habitação, pois é aqui que se revelam profundas desigualdades, impostas pelos acessos diferenciados da população à moradia, condicionada pela existência da propriedade privada do solo urbano. Tal fato sinaliza a principal contradição do processo de produção do espaço urbano: a cidade se produz de forma socializada, mas sua apropriação é privada. Esse processo faz aparecer por todos os lados a desigualdade entre o "rico" e o "pobre" (entre centro e periferia e dentro de cada um) e entre este e a "miséria absoluta" representada por aqueles que moram embaixo das pontes ou nos bancos das praças. A disparidade também se expressa nas construções, na existência e/ou na qualidade da infra estrutura, na roupa e nos rostos (na rudez ou suavidade de traços), no acesso aos espaços públicos.

O modo como a propriedade se realiza em nossa sociedade, construindo uma cidade de acessos desiguais aos lugares de realização da prática sócio-espacial - numa sociedade de classes - situa os homens dentro da cidade de forma diferenciada. A restrição ao acesso aos lugares da vida numa sociedade periférica - onde a industrialização poupadora de mãode-obra e realizada com altas taxas de exploração do trabalho deixou uma massa de força de trabalho em potencial fora do processo produtivo e obteve aumento de produtividade à custa da alta taxa de exploração da força de trabalho redundando em baixa remuneração - fez com que os trabalhadores mal pagos, informais, migrantes vivendo de bicos ou literalmente desempregados fossem ocupar as áreas menos valorizadas da cidade, isto é, aquelas onde a escassez de trabalho materializado no solo urbano redunda em preços mais baixos de terrenos. Aos sem renda ou com renda irrisória, este processo de industrialização reduziu os indivíduos à sua condição de sobrevivência e, com isso, à ocupação - por parte desta população - de áreas públicas, ou ainda, onde o direito de propriedade não vigorasse, o que produziu as favelas e áreas de ocupação na periferia. Evidentemente, o próprio sistema que produz esta ocupação vai reproduzir estes espaços também como mercadorias, articulados e submetidos ao mercado imobiliário - e é assim que, depois de formados, os barracos se tornam mercadoria.

Os terrenos de baixo preço ou sem valor de troca se situam em áreas impróprias à ocupação e à vida humana, o que vai gerar grandes catástro-

190. GeoTextos, vol. 3, n. 1 e 2, 2007. Ana Fani Alessandri Carlos 187-200 
fes ambientais e sociais. Portanto, trata-se de um processo que se reproduz tendo como conseqüência a deterioração: primeiro, do trabalho no processo produtivo e, com ele, de todos os sentidos do homem; depois da vida circunscrita à realização das necessidades animais; na seqüência, das áreas de realização da vida humana, a partir da moradia; depois, da natureza, e, finalmente, em seu conjunto, gerando a deterioração de toda a cidade e da vida na cidade. Processo este aprofundado pela ação do Estado que, através do direcionamento de suas políticas públicas, produz o processo de valorização-desvalorização dos lugares da cidade, pois a orientação das políticas redunda em distribuição de recursos aplicados nos lugares da cidade voltados para a valorização do valor e muito precariamente nos lugares periféricos. O dinheiro chega geralmente de forma assistencialista à periferia mediante uma catástrofe ou pressão da população residente nestes espaços.

Assim, o ato de morar revela o modo como o processo de segregação se realiza espacialmente, iluminando uma prática estratificada e hierarquizada em função da renda/classe social. Por outro lado, também revela uma diferenciação de usos que entram em conflito, na medida em que são contraditórios os interesses dos vários segmentos da sociedade, contrapondo ao processo de valorização, como condição da reprodução econômica, as necessidades da reprodução da vida em sua dimensão plena na construção dos espaços de sociabilidade. Como os interesses e as necessidades dos indivíduos são contraditórios, a ocupação do espaço não se fará sem lutas. Neste sentido, o movimento da reprodução das cidades revela os conflitos e limites da reprodução social, apontando a contradição entre valor de uso e valor de troca do espaço. Isto é, as possibilidades de produção da cidade, visando à realização da vida humana, entram em contradição com o processo de valorização do espaço, no sentido de criar possibilidades para a reprodução continuada, seja econômica ou política. É assim que as transformações revelam-se enquanto crise. Como conseqüência, a cidade tende a aparecer como um caos que necessita ser organizado.

Assim, a produção da segregação revela, em seu fundamento, a negação da vida na cidade. Refere-se ao movimento de passagem da cidade produzida enquanto lugar da realização da vida para a cidade reproduzida 
sob os objetivos da realização do processo de valorização, a partir de estratégias imobiliárias associadas, hoje, ao capital financeiro.

Nesta lógica o mundo urbano revela uma profunda transformação nas relações da sociedade com os espaços-tempo enquanto momento e movimento da reprodução da sociedade saída da história da industrialização, em direção à constituição de uma sociedade apoiada em novos padrões sociais e estéticos que não deixam de invadir também o campo, transformando-o.

A desigualdade espacial aprofunda-se, nas grandes metrópoles o deslocamento dos estabelecimentos industriais é um fato que ilumina a passagem da hegemonia do capital industrial ao capital financeiro, do mesmo modo constatamos uma maior taxa de crescimento urbano nas chamadas cidades médias do que nas áreas metropolitanas, principalmente São Paulo e Rio de Janeiro. Nestas, o adensamento das vias expressas, a construção dos túneis e viadutos, associada ao crescimento do setor imobiliário ligado ao setor financeiro, que produz os grandes edifícios inteligentes voltados aos setores modernos da economia, redefinem a centralidade urbana, com a expulsão de uma população "não compatível com as mudanças", fazendo crescer a periferia, já inflada pelo processo de industrialização. O crescimento do capital financeiro, que a partir do desenvolvimento das comunicações e a expansão da informação aprofundou e redefiniu as relações entre os lugares na hierarquização espacial entre espaços dominados/dominantes, sob o comando da metrópole nacional, permitiu de forma contraditória a integração dos espaços ligados aos setores globalizados da economia - direcionando, para aí, seus investimentos enquanto ampliava os espaços da desintegração, as periferias. Isto é, a extensão do capitalismo, a partir de profundas transformações no processo produtivo, do desenvolvimento do mundo da mercadoria como condição desta extensão, da passagem da predominância do capital industrial para o financeiro, dominando o mundo, produziu um novo espaço hierarquizado em rede, um novo modo de vida na cidade, e uma nova articulação cidade/campo, pela mediação do agronegócio, adensando as áreas periféricas e aprofundando a desigualdade. É bem verdade que há indicadores positivos, como a diminuição da taxa de mortalidade infantil, da taxa da natalidade, e aumento de residências abastecidas com sanea- 
mento básico a partir dos anos 1990, mas esse processo ocorreu juntamente com o aumento do desemprego, do trabalho informal, das favelas, da violência e da concentração de renda nos espaços urbanos.

No conjunto do território nacional, a metrópole de São Paulo centraliza o capital acumulado, principalmente o financeiro, articulando praticamente toda a produção agrícola brasileira como conseqüência da centralização. Com a desigualdade no campo, o desenvolvimento avançou, reproduzindo relações especificamente capitalistas, implantando o trabalho assalariado sem que as relações camponesas desaparecessem totalmente e sem que a totalidade do trabalho no campo e da vida fosse submetida integralmente à sujeição real do capital, apesar do desenvolvimento da industrialização, da agricultura e da expansão das culturas para exportação no seio da economia global. Este processo tende a englobar espaços urbanos e rurais numa nova lógica, onde a existência da propriedade privada marca e limita as possibilidades de apropriação, reorganiza o processo produtivo, arrasta para a periferia das cidades uma população que ainda trabalha no campo, regularizando a vida. A cidade e o campo vão refletindo o modo como se realiza a inserção do Brasil no quadro da economia mundial, onde a metrópole aprofunda sua centralidade em relação a um território mais amplo, o que permite a expansão-contração das áreas de cultura de exportação, apoiada na estrutura moderna, sob seu comando. Mas a metrópole paulistana também centraliza a informação, as atividades culturais, de ciência e tecnologia, bem como se transforma num pólo de atração do que se chama de turismo de negócios - com a ampliação do número de feiras, congressos, etc.

O Estado tem um papel fundamental no processo, com a ascensão do neoliberalismo e a decorrente inserção competitiva do Brasil na economia globalizada. Com isso, o direcionamento das políticas públicas, que passam a estimular os setores competitivos da economia a partir dos centros urbanos, interferindo, objetivamente, na reprodução espacial, seja financiando a agricultura capitalista e deixando de lado as pequenas unidades camponesas que produzem a alimentação básica dos trabalhadores, seja direcionando a localização industrial, ou ainda investindo em infra-estrutura capaz de permitir o crescimento do setor de serviços, seja através da gestão empresarial da cidade. Esse processo revela como tendência a cons- 
trução da sociedade urbana, onde a cidade vai ganhando cada vez mais importância como centro de acumulação e do poder político, mas também permitindo a reunião dos poderes que entram em confronto com a lógica da acumulação, revelando os conflitos de uma sociedade de desiguais. Isto porque a expansão do capitalismo se fez às expensas de grande parte da sociedade brasileira que vive nos limites da sobrevivência, revelando uma crise social: segregação, hierarquização dos lugares e cidadãos na cidade, apontando novos conteúdos da urbanização.

A sociedade assentada no sistema produtor de mercadorias, fundado na existência da propriedade da terra, dos meios de produção e do dinheiro, que, ao se desenvolver, não só inundou o mundo de produtos sempre novos, assentados na obsolescência forjada e na moda que introduz o efêmero, mas também produziu um conjunto de relações sociais subsumidas a esta lógica e que revela, também, sua crise. Primeiramente a degradação da força de trabalho, que destrói as capacidades humanas, limitando-as à condição de medida de tempo pelo trabalho mecanizado, de tarefas autonomizadas, destituído de suas qualidades e que, nesta dimensão abstrata, invade a sociedade, enquanto a reestruturação produtiva tornou uma parcela dos trabalhadores dispensáveis, aumentando as taxas de desemprego. Deste modo, ao mesmo tempo em que a produção de massa vai exigindo o consumo de massa, produz-se contraditoriamente uma parcela significativa de população que terá acesso apenas residualmente ao mercado de consumo, pois o processo de produção capitalista produz um vasto contingente de força de trabalho supérflua tanto na cidade quanto no campo; uma massa significativa crescente que se encontra vivendo daquilo que sobra e em condições de precariedade.

À crise social e econômica associa-se uma outra conseqüência, a deterioração da natureza (provocando a poluição do ar, da água, o esgotamento, etc.), que, pelo processo de produção, tornou-se recurso no processo histórico na condição de força produtiva para o capital, que, assentado no lucro imediato, produziu sua destruição. Mas que, contraditoriamente, faz da degradação da natureza uma nova mercadoria e, nesta condição, a natureza entra, novamente, no circuito de valorização (caso da "venda do verde" incorporada aos lugares, que movimenta não só mercado imobiliá- 
rio - a construção e venda dos condomínios fechados calcadas na proximidade da natureza ausente na cidade - mas, em suas novas estratégias, faz do "turismo ecológico", um novo e poderoso setor da economia).

A implicação das crises econômica, ecológica e social produz a degradação da cidade, introduzindo uma crise urbana (em profundidade social ou ainda sócio-espacial) que pode ser constatada no fato de que: a) na medida em que o sistema se expande o espaço produzido enquanto prática sócio-espacial esvazia-se; na cidade, a propriedade revela novos usos do espaço a partir das articulações entre os momentos do lazer, do trabatho e da vida privada em lugares estabelecidos com funções rígidas, e, como conseqüência, todos os lugares da prática sócio-espacial, produto da contradição entre o espaço produzido na perspectiva do valor de uso (destinado à realização da vida) e aquele do valor de troca, com a submissão quase total do primeiro ao segundo; b) a expansão do sistema induz a extensão da propriedade tomando todos os lugares da cidade e criando, através da extensão do valor de troca do espaço, acessos diferenciados da população à habitação. A extensão deste processo, ao ganhar potência criativa - construindo a cidade moderna -, adquire potência destrutiva. O que se destrói são os lugares da vida em detrimento da lógica da reprodução dos espaços produtivos para a realização econômica em sua lógica reprodutora; c) a necessidade constante de fluidez no tempo e no espaço produz na cidade uma significativa rede de circulação; d) o desenvolvimento do sistema exige uma relação de alianças entre o poder político e o econômico - no Brasil este colamento é evidente - as classes detentoras do capital e da terra são ou estão estreitamente ligadas ao poder político. Daí a instauração de políticas urbanas compatíveis ou estimuladoras da produção constante de uma cidade compatível com a lógica da reprodução; e) trata-se de um processo de reprodução que ao ganhar toda a sociedade vai impondo um modo de vida num novo espaço - aqui a necessidade da reprodução econômica entra em contradição com a reprodução da vida, gerando conflitos associados à intervenção pública no espaço urbano. Deste modo, vai se revelando a implicação de quatro dimensões da crise produzida pelo desenvolvimento do capitalismo na periferia do sistema e vivida tão desigualmente pela sociedade brasileira, escancarando a dialética do mundo e produzindo as lutas na e pela cidade. 
Na cidade, a luta "dos sem teto", por exemplo, desloca a luta da esfera produtiva (revelando a contradição intrínseca ao capitalismo entre operário e capitalista) para a esfera da reprodução da vida em seu sentido mais amplo, com isso sinaliza a reprodução ampliada das relações sociais de produção para além da produção estrita de mercadorias. Esta luta se realiza questionando a propriedade na cidade, que revela o processo de deterioração e desintegração da vida, colocando em xeque o direito da propriedade privada e as formas de apropriação do espaço enquanto condição de realização da vida, seja para a produção do alimento, seja enquanto moradia e tudo o que esta atividade implica para a vida. Revela, por sua vez, a produção segregada do espaço, a privação, enquanto produto, no mundo moderno, do modo como se realiza a reprodução das relações sociais no Brasil.

\section{A prática urbana como cisão}

Os problemas atuais postos pela urbanização que ocorrem no âmbito do processo de reprodução da sociedade revelam uma prática espacial urbana permeada pela separação/dissociação dos elementos da vida. Nesta dimensão, no plano do vivido, o espaço e o tempo se apresentam entrecortados, em fragmentos, por atividades divididas e circunscritas e o habitar, enquanto ato social, vai desaparecendo na medida em que a habitação se reduz ao abrigo ou à fuga. Por sua vez, ao se desenvolver, o processo também criou comportamentos padronizados, modelos éticos, estéticos, gostos, valores, moda, constituindo-se como elemento fundamental da reprodução das relações sociais, a partir não só de espaços mas também de um cotidiano normatizado e programado, onde todas as relações sociais, mediadas pela mercadoria, dão origem a um nova urbanidade marcada pela dissolução de relações sociais que ligavam os homens entre si, bem como na vida familiar e social. As relações com novos objetos, dentre eles a TV que banaliza tudo (da religião à política), se impõem através de seu poder hipnótico extraordinário, definindo gostos, orientando hábitos, criando opiniões, encantando com a produção de um espetáculo colorido de imagem. A segmentação da atividade do homem, 
massacrado pelo processo de homogeneização, torna as pessoas "pasteurizadas" e, nesta condição, "idênticas", com isso produz a submissão ao consumo e à troca como condição da reprodução das relações sociais, onde o uso se defronta com as restrições sempre ampliadas da propriedade privada, que, em seu crescimento, esvazia as possibilidades de realização da vida humana. Resta às pessoas se diferenciarem no universo diferenciado da moda segmentada por estratos - mesmo assim, realizando a diferenciação na condição universal de consumidores.

O lazer na sociedade moderna também muda de sentido, apontando outra cisão: de atividade espontânea, busca do original como parte do cotidiano, passa a ser cooptado pelo desenvolvimento da sociedade de consumo, que tudo que toca transforma em mercadoria, tornando o homem um elemento passivo deste processo. Tal fato significa que o lazer, tanto quanto o turismo, tornam-se "novas necessidades" de consumo. Isto é, no curso do desenvolvimento da reprodução das relações sociais, produz-se uma nova atividade produtiva diferenciada, com ocupações especializadas, que produz um novo espaço e/ou novas formas de uso deste espaço.

Constata-se, no mundo moderno, que as transformações aceleradas provocadas pelo processo de globalização, como produto de desenvolvimento do capitalismo, fazem da produção do espaço um elemento fundamental da reprodução na medida em que, tornado mercadoria, o espaço, através de suas particularidades, entra na troca, através do consumo turístico, que aparece em todos os lugares como possibilidade de renda para muitos municípios. A construção dos modernos aeroportos em muitas cidades nordestinas, associadas a um agressivo marketing para atrair turistas para suas praias, bem como a revitalização dos centos históricos de muitas cidades brasileiras, sinalizam estas mudanças.

A produção dos espaços de turismo e de lazer se realiza como conseqüência do desenvolvimento do mundo da mercadoria, que, num determinado momento da história, produz o espaço enquanto valor de troca, numa sociedade em que todos os momentos da vida cotidiana se acham penetrados e dominados pela realização da mercadoria suscitada pela extensão do capitalismo. O turismo revela, assim, a mudança da relação espaço-tempo no mundo moderno, realizando o espaço enquanto merca- 
doria, ao mesmo tempo em que submete o tempo do lazer ao mundo da mercadoria. Esta atividade se realiza realizando o consumo produtivo do espaço - onde o atributo do lugar constitui a representação necessária que orienta o uso. É assim que, o turismo aparece, no mundo moderno, como uma nova possibilidade de realizar a acumulação, que, em sua fase atual, liga-se cada vez mais à produção do espaço - produção que se coloca numa nova perspectiva, onde o espaço ganha valor de troca enquanto possibilidade de realização do valor de uso.

Na contrapartida, a cidade se opõe ao indivíduo enquanto objeto estranho; como potência independente; a alienação se estende por toda a vida do habitante revelando uma crise que se aprofunda e ganha visibilidade, nas grandes metrópoles, com aumento das tensões e da violência como conseqüência das contradições pela diferença entre miséria e opulência; com o aumento do número dos sem teto que moram nas ruas centrais, bem como o aumento do número de meninos de rua - com a presença crescente de crianças que cheiram esmalte, cola de sapateiro, craque. Com a mudança do sentido e conseqüente uso do espaço público presencia-se a privatização pelos camelôs - que se apropriam privativamente do espaço público - o gradeamento e fechamento de praças em nome da segurança; o fim das ruas como o espaço do caminhar e do estar/do flanar; a construção de guaritas nas ruas de bairros chamados nobres, e a construção dos condomínios fechados e vigiados por milícias particulares. O aumento do poder do "narcotráfico", organizando áreas crescentes da metrópole, delimita os espaços da vida bem como o ir e vir; enquanto as ocupações de solo urbano em número sempre crescente sinalizam a carência. Mas também, só no município de São Paulo, existiam, em 1990, 611 milhões de metros quadrados de terrenos vazios, dos quais, 158 milhões pertenciam à esfera privada (correspondendo a 15 mil quarteirões, em sua maioria localizados na periferia).

Estes elementos destroem a natureza social da cidade, deixando os conteúdos da urbanidade submetidos à predominância do objeto - os homens se relacionam com um conjunto de objetos que regem as relações sociais, posto que substituem, cada vez mais, as relações diretas entre as pessoas, produzindo, em seu desenvolvimento, a identidade abstrata separação abissal entre o sentido da mercadoria dado pelo uso e o seu 
valor simbólico na sociedade de consumo. Nesse contexto, a mercadoria absoluta criou o maravilhoso espetáculo do valor de troca, presente nas grandes cidades, revolucionando o modo de vida.

\section{A cidade como direito}

No final dos anos 1980, inaugura-se uma nova constituição e, com ela, o "estatuto da cidade", como produto das lutas patrocinadas pelos movimentos sociais que estão na base da sociedade brasileira como aquele pela reforma urbana. A lei federal 10.257 criou uma nova base jurídica para o desenvolvimento urbano, com mudanças sobre o direito à propriedade (incorporando a noção de direitos urbanos, estabelecendo uma função sócio-ambiental para a cidade e uma função social para a propriedade da terra urbana) e promovendo a participação da população na gestão da cidade. Trata-se de um passo decisivo para o que viria na virada do novo século: a constituição de um ministério das cidades, bem como da realização das "conferências das cidades" em seus vários âmbitos (local e nacional), realizadas em quase todo o Brasil. Este fato relativiza a indiferença do Estado diante da desigualdade que fundamenta a produção das cidades capitalistas, colocando na ordem do dia o debate sobre o "direito à cidade", trazendo como conseqüência a possibilidade de uma "gestão democrática" para a cidade onde os cidadãos "são convidados" a participar da elaboração do orçamento do município bem como dos conselhos da cidade.

Sem negar esse avanço, é, no entanto, necessário dialetizar seu papel na constituição de um projeto capaz de sinalizar as transformações necessárias da cidade como momento de transformação radical da sociedade, na medida em que o direito à cidade reduz-se quase exclusivamente "ao direito à moradia mais serviços" e não questiona, senão reforça, em nossa sociedade, o papel e a existência da propriedade privada da terra como direito (inviolável e sagrado) constitucional, vindo da história - da declaração da independência americana, seguida pela revolução francesa, promulgada na declaração dos direitos humanos, estabelecida na constituição brasileira. 
O homem habita, percebe e vivencia o mundo a partir de sua casa uma realidade objetiva e povoada de objetos - que ganha sentido à medida que a vida se desenvolve ao longo do tempo, praticamente. Assim, a habitação envolve outras dimensões espaciais como a rua, depois o bairro, criando o quadro de articulação espacial no qual se apóia e realiza a vida cotidiana. Como decorrência, as formas materiais arquitetônicas guardam um conteúdo social vindo da prática espacial enquanto modos de usos dos lugares. Através do uso, do corpo em ato e movimento, nas atividades mais banais da vida, os habitantes se relacionam com o outro, se identificam, conferindo um conteúdo à vida e aos lugares. O habitar cria e interliga um conjunto de ações em planos e escalas espaciais entre o público e o privado, entre o indivíduo e a coletividade - o homem imerso numa teia de relações que constrói uma história particular que é, também, uma história coletiva. Portanto, a condição da reprodução da vida humana, articula dois planos: o individual (que se revela, em sua plenitude, no ato de habitar) e o coletivo (que diz respeito à reprodução da sociedade). Assim, o sentido do habitar é muito mais amplo que o espaço da casa e da infra-estrutura (incluindo escolas, postos de saúde, etc.). Nesta perspectiva, o "direito à habitação" é fundamental na constituição da cidadania, mas insuficiente, o que coloca ainda a necessidade de luta pela conquista do "direito a cidade", como direito à vida urbana e tudo o que ela implica. Este é o desafio do novo século. 